\title{
DANÇA E MEDIALIDADE: PARA UMA DISCUSSÃO ONTOLÓGICA E ÉTICA DO CORPO PERFORMATIVO
}

\author{
Né Barros
}

\begin{abstract}
Resumo
A partir dos finais do século XIX podemos assistir a pelo menos duas grandes mudanças nos posicionamentos poéticos sobre a dança, introduzindo, assim, maiores desafios ao pensamento filosófico e estético sobre esta arte. A primeira mudança poderia ser identificada como rutura com um legado, uma rutura coincidente com todos os passos dados pela dança moderna ocidental e, em particular, pela americana. A segunda mudança poderia ser identificada com a expansão das fronteiras da dança, onde se inclui todo o processo de indefinição disciplinar e de género artístico. A rutura e a expansão são mudanças assinaláveis que também podem ser enquadradas num pensamento pós-metafisico. Este domínio expandido e inclusivo do outro pode ainda ser pensado através de uma techné que não se confunde com engenho ou mera capacidade do artífice, ou ainda como eros alienante, mas também como domínio da performatividade enquanto jogo de autorização e desautorização (autoria envolvida no confronto com o outro), tornando-se, por isso, terra de ninguém. Neste campo aberto e indefinido, o corpo dançante revela-se palco político e ético por excelência (performance) e espaço ontológico abrangente (performatividade). É este o âmbito da nossa discussão que encontra na medialidade o domínio comum destas duas abordagens à dança.
\end{abstract}

\section{Palavras-chave}

Corpo; discurso; medialidade; performatividade

\begin{abstract}
From the late nineteenth century we can see at least two major changes in the poetic positions in dance thus pose major challenges to philosophical and aesthetic thought about this art. The first change could be identified as a break with a legacy, a coincidental break with all the steps done by western modern dance and in particular the US. The second change could be identified with the expansion of the frontiers of dance, which includes the whole process of blurring of artistic discipline and artistic genre. The rupture and expansion are, therefore, noteworthy changes that can also be classified in post metaphysical thought. This expanded and inclusive domain of the other can still be thought through a techné not to be confused with ingenuity or the mere ability to artificer, or as an alienating eros, but as the field of performativity as permition for play and disempowerment (questioned authorship in comparison with the other), becoming therefore no man's land. In this open and undefined field, the dancing body reveals itself as the political and ethical stage par excellence (performance) and an ontological space (performativity). This is the scope of our discussion that finds in mediality the common domain of these two approaches to dance.
\end{abstract}

\section{Keywords}

Body; discourse; mediality; performativity 


\section{INTRODUÇÃo}

O século XX não deixou dúvidas sobre a condição da dança enquanto expressão de arte autónoma. A dança ocidental foi exemplar no seu desenvolvimento e revelou ser uma matéria séria para as reflexões sobre a arte em geral. Nem sempre foi assim, e é, em parte, essa transição que nos inspira o desenvolvimento deste texto. Afirmada a dança, esta passa a ser um domínio privilegiado de questionamento do corpo, em particular do corpo performativo. E o que discutiremos é o corpo performativo enquanto objeto de uma ontologia e de uma ética da forma'. Para esta discussão, partimos do contributo assinalável dos chamados poetas-filósofos pela introdução de novos paradigmas na reflexão sobre o papel da dança, devolvendo-lhe um estatuto ontológico. Seguidamente, prosseguirmos para um questionamento da dança enquanto dispositivo (configuração fundamental para pensá-la na contemporaneidade).

É, portanto, a partir dos finais do século XIX que se pode assistir a, pelo menos, duas grandes mudanças nos posicionamentos poéticos na dança, colocando, assim, maiores desafios ao pensamento filosófico e estético sobre esta arte. A primeira mudança poderia ser identificada como rutura com um legado, a rutura que a dança moderna ocidental e, em particular, a americana produziu com os seus princípios e posicionamentos. A segunda mudança poderia ser identificada com a expansão das fronteiras da dança, onde se inclui todo o processo de indefinição disciplinar ou de género artístico. A rutura e a expansão são, portanto, as mudanças assinaláveis que também podem ser enquadradas num pensamento pós-metafísico. Ou seja, por um lado, assiste-se à introdução do corpo como a noção que obriga a repensar as tradicionais dicotomias - como a do corpo e alma - substituindo todo o aparato transcendente pelo elogio do imanente. É disto que trata a rutura com o paradigma da bailarina ideal, substituída pela bailarina descalça que não ilude o centro de gravidade. Sabemos que sobre esta bailarina terrena não fica completamente desativada a possibilidade de uma interpretação transcendente, contudo, operativamente, do ponto de vista poiético, a perda de interesse por um corpo de aparência assumidamente artificial traduz a vontade de retornar ao mundo e a uma corporalidade residente na vida mundana e, assim, colocar a sensação no corpo-peso-pesado. Por outro lado, dada a proliferação de novas abordagens ao corpo-em-movimento, torna-se necessário repensar o gesto na sua abrangência performativa e virtual que permita uma deslocação de termos, perspetivas e dimensões, desestabilizando identidades primárias de forma irreversível. É neste efeito de deslocação que podemos perceber a substituição do fim pelo meio e da célula identitária pelo jogo de circulação entre o eu e o outro, que acentuam um movimento ético na construção das formas em geral, e da forma dançante em particular.

Este domínio expandido e inclusivo do outro pode ainda ser pensado através de uma techné que não se confunde com engenho ou a mera capacidade de artífice, ou ainda um eros alienante, mas que respeita ao domínio da performatividade enquanto jogo de autorização e desautorização (autoria envolvida no confronto com o outro), tornando-se,

' Em Da materialidade na dança (Barros, 2009) é iniciada uma discussão sobre a necessidade de se entender o corpo dançante não apenas na dimensão estética, mas também na dimensão ética. 
por isso, terra de ninguém. A techné, enquanto prolongamento de uma corporalidade sempre reinventada, como teatro de reinvenção de novos corpos, enquanto performatividade, parece, mais do que nunca, projetar-se em toda a prática performativa, fazendo-a viver num lugar sem fronteiras e sem pátria².

Em síntese, podemos distinguir dois domínios fundamentais de questionamento na reconfiguração do corpo dançante: o da performance (palco político e ético por excelência) e o da performatividade (espaço ontológico abrangente). Duas abordagens à dança que encontram na medialidade o seu domínio comum de discussão.

\section{Performance: gesto enquanto expansão e Abertura do ethos}

Desde o abandono da coreografia na sua versão mais notativa e discreta até ao avançar para a versão expandida onde sujeito e objeto se confundem, é neste percurso que as identidades se problematizam ao infinito. A própria noção de performance parece encontrar uma sustentação nestas mudanças e neste novo paradigma. Historicamente ligada às artes plásticas, a performance acabou por se disseminar por outras expressões e, em particular no caso da dança, contribuir para o esbatimento da sua própria definição. Recordemos o que nos diz Rose Lee Goldberg sobre o assunto:

a performance pode ser a série de gestos íntimos ou a larga-escala teatral que pode durar uns escassos minutos ou horas; pode ter uma única atuação como ser repetida várias vezes, com ou sem guião preparado, improvisado espontaneamente ou longamente ensaiado. (1990, p. 8)

\section{A autora procede dizendo que}

pela sua própria natureza, a performance desafia qualquer definição precisa ou fácil para além da simples afirmação de que é arte feita ao vivo por artistas. Qualquer definição mais estrita negaria imediatamente a própria possibilidade de performance em si, pois a performance usa livremente quaisquer disciplinas e meios - literatura, poesia, teatro, música, dança, arquitetura e pintura, assim como vídeo, filme, projeções e narrações-, utilizando-os nas mais diversas combinações. (Goldberg, 1990, p. 9)

Sabendo do estado da dança hoje, no extremo, poderíamos inferir uma assimilação do termo dança pela performance que nos levaria muito longe 3 . Independentemente da discussão que se possa estabelecer em torno desta formulação, o que se verifica, en-

\footnotetext{
${ }^{2}$ A propósito deste assunto, no seu projeto sobre o domínio da performatividade, Filipe Martins (2016) diz: "a techné começou certamente por ser uma consciência do próprio corpo e da sua potencialidade instrumental. A partir daqui o corpo, enquanto espaço originário da mimesis, só poderá estender-se; e estender-se-á justamente através da techné. O artefacto é, no fundo, um prolongamento do sujeito, uma extensão protésica, um alargamento da corporeidade, cujas possibilidades são, em princípio ilimitadas (...). Em suma, a techné é um canibalismo do real e, ao mesmo tempo, dirige o projeto histórico da edificação alargada do sujeito" (p. 308).

3 Uma discussão que nos levaria longe: em causa poderia estar o facto de, hoje, já não se tratar de entender a dança na era da performance, como alguns autores tendem a fazê-lo, mas de assumir a performance como o que resta da mutação que a dança sofreu.
} 
tão, é um estado de abrangência contextual a partir do qual interessa saber o que se joga no gesto performativo e o que o faz ser performativo. No curso de uma pós-metafísica e de uma pós-história, será ainda necessário e possível proceder a uma distinção do gesto que não envolva novas formas categóricas? Ou seja, existe, nesta abrangência produtora de formas expandidas, a necessidade de recuperar uma discussão ontológica não de fundamentos, mas de modos fundamentais de ligação do corpo ao mundo.

Historicamente, percebeu-se como essencial a introdução do corpo na problematização desta evolução, em particular porque o corpo faz da revisitação da dança uma reinterpretação do mundo, já que a relação corpo-alma se substitui por aquela corpo-mundo. Aliás, a fenomenologia, na sua grande tese, substitui a relação corpo-alma pela relação corpo-mundo, e a dança será a metáfora perfeita deste modo de pensar e estar na vida. Friedrich Nietzsche, apesar de não ter escrito nenhum texto genuinamente sobre a dança, será o autor para quem a dança é metáfora do pensamento, ao mesmo tempo que, através da dança, se podem entender as dinâmicas do mundo. Como nos diz Giorgio Agamben (1997, p. 18): "assim falava Zaratrusta é o ballet de uma humanidade que perdeu os seus gestos". Esta dança, compassada de uma humanidade que se vai tornando autómata ou indiferenciada, reclama o pensamento de um corpo que é preciso recuperar, onde é preciso voltar. Esta mudança de plano que o corpo do dançarino de Nietzsche promove - o retorno à sensação e o abandono da forma rígida ideal - coincide duplamente com o que subjaz aos princípios da dança moderna e da revolução filosófico-poética. O corpo é o protagonista de uma procura originária. O gesto criador reside num corpo e é neste ato que o homem encontra sentido. A morte de Deus decorre desta perda de sentido dado exclusivamente pela relação com um absoluto e com o transcendente.

A dança revela-se inspiradora e o melhor exemplo vivo desta mudança paradigmática: a dança é corpo real e virtual que se projeta através do ser-em-gesto. Para além da dança ser entendida como metáfora de pensamento (Nietzsche), há que pensá-la nas suas tensões com a filosofia e com a poesia, daí que muitos autores se tenham entusiasmado com a possibilidade destes envolvimentos. Rainer Maria Rilke (1875-1926) também terá revelado o seu interesse pela dança e terá expressado o desejo de escrever uma poesia para Vaslav Nijinsky (1889?-1950), o carismático bailarino e coreógrafo dos Ballets Russes considerado como referência para o segundo modernismo na dança. RiIke ciatdo em Sorell (1994, p. 374) terá dito: "devo fazer uma coisa para Nijinsky... uma poesia que, por assim dizer, deva ser primeiro absorvida e depois dançada" 4 . Algo que está na continuidade do que dirá ainda Rilke citado em Sorell (1994, p. 375) no Diálogo: "os dançarinos criam imagens, mas não se explicam".

A dança transporta esta possibilidade de metamorfose sem a necessidade de se prender a narrativas figurativas, e, por isso mesmo, revela-se uma área privilegiada de analogia ao movimento do próprio pensamento (enquanto movimento do devir forma). Também por esta razão, a dança, que até ao século XIX esteve afastada dos circuitos de pensamento capazes de the conferir densidade como forma de arte autónoma, revela-se objeto de particular interesse para os chamados poetas-filósofos. O discurso sobre a

${ }^{4}$ Lembra-nos Walter Sorell do interesse de Rilke sobre este bailarino a partir da carta à princesa de Thum und Taxis. 
dança passa a ser um discurso que investiga e recupera valores primordiais e antropológicos da dança enquanto representação e não apenas como modalidade de entretenimento. Os textos Ballets (1886/1976) e Autre étude de danse. Les fonds dans de le Ballet. D'après une indication récente (1893/1976), de Stéphane Mallarmé, são dos grandes testemunhos da assunção da dança como forma de arte e da relevância que esta conquista no campo da reflexão.

Efetivamente, a dança enquanto género autónomo deve-se a esta relação mais intensa entre a multiplicação e expansão das poéticas e o olhar crítico capaz de identificar a sua fenomenologia e os seus complexos processos significativo-comunicativos. Loïe Fuller, um dos exemplos justamente muito citados, é uma das primeiras coreógrafas americanas a chegar à Europa, a quem Mallarmé se vai referir. Sabemos que a sua importância se revia nas novas soluções de iluminação que respondiam às necessidades da época em alterar o aspeto do teatro. As novas valências que a luz conquistava juntavam-se aos requisitos de uma renovação do teatro que não passasse exclusivamente pelo drama, mas pela imagem concreta da cena, pela cenografia, iluminação e novos métodos de produção. ${ }^{5}$

Há, ainda, outras danças que estão a surgir e que inspiram pensadores como Paul Valéry (1957), que publica um texto em 1938 (Philosophie de la danse) a partir da teatralização da dança de rua da famosa Argentina ${ }^{6}$. Fazendo a distinção entre Leib (o corpo como corporeidade vivida e em si própria expressiva) de Körper (o corpo enquanto corpo-objeto), Valéry entende a dança como criação corêutica coincidente com a dinâmica corpórea do seu próprio criador. Com L'âme et la Danse (escrita durante o ano 1921), obra-chave destas reflexões, Valéry ocupa-se mais com os princípios pelos quais a bailarina é realidade dançante no mundo do que com o domínio mais puramente simbólico da obra, como acontecia em Mallarmé'. Por um lado, é na aliança entre poesia e filosofia que podemos reconhecer o contributo de poetas como Mallarmé, Valéry ou Nietzsche. Por outro lado, o filósofo-artista ensina-nos a voltar às origens para reencontrar laços fortes nos movimentos de dança, movimentos capazes de acolher as categorias da vida.

Este modo de escrita traçado pelos referidos poetas-filósofos ou filósofos-artistas, associado a um pensamento não sistemático, um pensamento que faz contas com a ambiguidade, o contraditório, a dialética ou a fragilidade, como se foi referindo, revela-se pertinente na abordagem a formas expressivas como a dança. Ao mesmo tempo, a introdução da noção de corpo potencial, já não discreto e separado, abre novos horizontes expressivos e transgride as categorias e a instituição da arte, superando a mera

\footnotetext{
${ }^{5}$ Esta possibilidade plástica, a par do abandono de formas rígidas, como a dança académica propunha, com as quais Isadora Duncan rompe definitivamente, gera a rutura necessária para que a dança se refunde como género autónomo e reivindique o estatuto autoral.

${ }^{6}$ La Argentina (Antónia Mercé, 1890-1936) nasceu em Buenos Aires, mas cedo foi para Espanha. A combinação do folclore espanhol com a dança académica, juntamente com o seu instinto dramático, revelou-se surpreendente na realização de um produto artístico.

7 Assumindo-se como discípulo de Mallarmé, Valéry terá hesitado, como ele próprio confessa, em escrever a sua obra sobre dança, já que, segundo ele, Mallarmé teria dito tudo sobre o tema. No entanto, e apesar de em ambos a dança em estado puro ser um ponto de partida para ulteriores reflexões, Valéry tenta uma aproximação diversa.
} 
função social. É justamente o que faz Valéry, que desconecta a dança da sua versão social e lhe evidencia o seu estatuto ontológico; ou seja, a dança enquanto gesto desligado do agir. Como, então, entender estes gestos novos?

\section{PeRformatividAde E DisPoSITIVO: REVISITAÇÃo Do CORPO-EM-MOVIMENTO}

Se com a modernidade o paradigma se colocaria ao nível de uma autonomia, com a pós-modernidade o estatuto ontológico da dança discute-se a partir de uma heteronomia: um lugar onde se vão encontrar a multiplicidade de histórias. Como nos diz Michel Maffesoli a propósito desta mudança paradigmática: "não é mais a autonomia - eu sou a minha própria lei - que prevalece, mas heteronomia: a minha lei é o outro" (Maffesoli, 2011, p. 23). Assim, a pergunta como entender os gestos novos pressupõe que se admita, desde logo, uma identidade fragilizada. Como a pós-modernidade nos evidencia, mais do que no indivíduo, há que pensar na pessoa (persona) e, nas palavras de Maffesoli, na pessoa que desempenha diversos papéis nas tribos às quais adere implicando uma multiplicação de identidades. Diz Maffesoli:

cada qual só existe no e através do olhar do outro. E esse outro pode ser o da tribo por afinidade, o da alteridade da natureza, ou ainda o grande Outro que é a deidade. Fusões, confusões de diversas ordens que nos fazem recordar o mito dionisíaco. (2011, p. 23)

Nesta mudança da autonomia para a heteronomia, para um questionamento dos gestos emergentes que para além de romperem com categorias mais ou menos estabelecidas assumem valências mistas e contaminadas, haverá necessidade de confrontar pelo menos dois tipos de abordagens.

Em primeiro lugar, verifica-se a necessidade de validar os gestos através de um processo de identificação aberta: distintos, mas não aprisionados numa classificação. Vários são os exemplos de tentativas na identificação de gestos que, independentemente de com o tempo se revelarem estéreis, não deixam de ser relevantes para um aprofundamento do estatuto ontológico da dança. Doris Humphrey (1959) distinguia os tipos de movimento por gestos sociais, funcionais, rituais e emocionais, sendo que estes últimos seriam a matéria do próprio dançar. Numa abordagem diversa e numa lógica mais comunicacional, Alessandro Pontremoli (1997) designaria o "gesto corêutico" como aquele que melhor se aplica à dança. $O$ autor começa por distinguir o gesto mímico (mimese icónica, gesto naturalístico) do pantomímico (fortemente codificado e convencionado, gesto estilizado) para chegar ao gesto corêutico. Diz Pontremoli (1997, p. 29): "entre estes dois extremos parece encontrar-se, enfim, o gesto corêutico, aparentemente gratuito, assemântico, não convencional, aberto". Contudo, esta abertura não coloca em causa a ideia de comunicação. Sobre isto, o autor refere:

apenas aparentemente um fazer reenvia diretamente a si, na realidade encontra a sua mais correta colocação num horizonte do discurso constituindo-se como um dizer, como uma escrita, mesmo no caso das manifestações 
que programaticamente não pretendem mediar algum conteúdo, como, por exemplo, as coreografias de Merce Cunningham ou as de Lucinda Childs. (Pontremoli, 1997, p. 23)

Todo o aparato comunicacional está lá e acontece independentemente da intencionalidade do conteúdo a transmitir pela dança. As estratégias de composição coreográfica - enquanto abstração, não-figuração, composição sem narrativa lógica, no fundo, tentativa anti-representacionista - não resistem ao apelo imaginal (mundo atravessado por imagem, imaginário, simbólico e o imaterial) (Maffesoli, 2011, p. 24) que o corpo em movimento convoca, onde é sempre possível narrativizar o corpo em movimento. Diz-nos Pontremoli (1997, p. 35): “o suporte de um gesto não é nunca abstrato, é história de uma alma, polissémica revelação de um centro intencional, sobre o qual convergem todos os olhares e dos quais todos os olhares se movem".

Isto conduz-nos ao segundo ponto da abordagem à emergência de novos gestos, plurais. Ao romper-se com uma lógica de oposição entre meios e fins, como temos vindo a constatar, os gestos devem ser pensados na sua condição de medialidade. O gesto é entendido como suporte, como nos fala Pontremoli, ou como a medialidade de "comunicar uma comunicabilidade", como dirá Giorgio Agamben nas suas reflexões sobre o gesto e sobre a dança enquanto gesto. Agamben (1997, p. 20) especifica que:

se a dança é gesto, é (...) porque ela consiste inteiramente em suportar e em exibir o carácter medial dos movimentos corporais. O gesto consiste em exibir uma medialidade, em tornar visível um meio como tal. Nesse lance, o ser-no-meio do homem torna-se visível, e a dimensão ética é-lhe aberta.

A medialidade - enquanto o exibido - desloca-nos para uma abertura ética porque o homem se torna visível e interrompe-se um dado movimento alienante. Se recuarmos, não será por acaso que o teatro épico de Bertolt Brecht se constrói pela citação como ato político e ético, onde a citação é, sobretudo, interrupção, a tomada de posição contra um estado alienado. Como Walter Benjamin nota, a propósito do teatro épico de Brecht, a interrupção é procedimento fundamental na estruturação da forma porque se trata de um processo onde, mais do que o desenvolvimento das ações, se trata de representar situações. "Citar um texto implica interromper o contexto no qual reentra" (Benjamin, 1998, p. 131). E, segundo Benjamim (1998, p. 131): "o ator deve ter a capacidade de espaçar os seus gestos, como um tipógrafo as palavras. Este efeito pode ser obtido quando o ator cita a si próprio em cena um seu gesto".

Enquanto procedimento, a interrupção, para além de desmultiplicar gestos, gera intervalos que tendem a limitar a ilusão do público, ajudando-o a tomar posições críticas. Enfim, em causa estará a importância de não diminuir o poder argumentativo a favor do sugestivo nos modos de produção. Algo que, estrategicamente, na visão brechtiana, se consegue quando se opõe crescimento orgânico e montagem como diferença de tratamento entre a forma dramática do teatro e a forma épica do teatro, entre o "homem como dado fixo" e o "homem como processo". O efeito meta-discursivo assume um 
papel fundamental no modo como se geram e interpretam as imagens e, ao mesmo tempo, no modo como se desenha uma ética da forma: espaçamento, visibilidade de um desdobramento, expansão. Assim, o aparato de dispositivo da obra (estratégias e princípios de construção) é testado no confronto com o carácter medial do gesto e da abertura a que a obra se expõe.

É a partir da medialidade da obra que se permite a multiplicação de sujeitos e de processos de subjetivação no confronto entre corpos viventes e dispositivos (Agamben, 2009). É neste confronto comunicante que se deve pensar uma relação responsável entre os tradicionais emissores e recetores, uma relação sem hierarquias onde ambos elaboram e autorizam todo o discurso suscitado por um dado evento; e onde, mais do que estarem perante o evento, eles são evento. É, em princípio, esta desmontagem do dispositivo que o pode fazer mais acesso privilegiado a uma obra de arte e menos máquina de controle de saber e poder. A obra passa a constituir-se como o pretexto para um dado percurso discursivo alternativo e, por vezes, desvinculado de um processo rígido de identificação. A obra, mais do que objeto do belo, funciona como dispositivo que promove uma experiência estética sem campo fixo, mas elástico e aberto, onde a obra é capturada para ser reelaborada, para ser performada (e não apenas informada) ${ }^{8}$. O fechamento desta situação estará, porventura, no sentido em que a sensação perante a obra parte do campo configurado da experiência que o dispositivo permite criar, mas como esse campo é ausente de regras, torna-se ele mesmo moldável e mutável pela possibilidade de nos posicionarmos livremente perante o que vamos fruindo. Há um limite que o dispositivo impõe, mas pela redução de possibilidades e não pela definição do padrão a gerar. (Daqui decorre a importância do factor responsabilidade na construção do dispositivo). O que se apresenta fenomenologicamente é materializado por um posicionamento determinado quer pelo performer quer pelo espectador, evidenciando-se a dimensão ética (tomada de posição e modo de ação sobre essa experiência).

Alargado o já lato termo utilizado por Foucault, o dispositivo, segundo Agamben (2009), pode ser qualquer coisa capaz de capturar, orientar, determinar, intercetar, modelar, controlar e assegurar os gestos, as condutas, as opiniões e os discursos dos seres viventes. Os dispositivos são incessantemente capturados pelos seres viventes e podem ser de natureza vária, até a própria linguagem, segundo o autor, pode ser considerada um dos mais antigos dispositivos (Agamben, 2009, p. 41). Neste alargamento podemos entender a obra de arte enquanto dispositivo no sentido de proporcionar um campo de reelaboração ética da relação, agora dinâmica, múltipla e imprevisível, entre emissor e recetor. O domínio económico desta relação consiste no domínio dos termos em que a obra se apresenta ou se reconhece. Será por esta via que gestos emergentes lançados pela dança na era pós-moderna, estrategicamente, desfuncionalizam as categorias estabelecidas (seja o ballet, seja a dança moderna). Ao mesmo tempo que se traz à dança gestos do mundo, gestos de todos os dias - gestos familiares onde se pode reencontrar novas potências da intervenção e papel da dança no panorama geral das artes -, gera-se

\footnotetext{
${ }^{8}$ Ver Martins, 2016.
} 
estranheza na categoria onde esses gestos se colocam gerando, assim, ao infinito, a dúvida se será ou não de dança que se trata.

É, portanto, no âmbito desta problematização, já não tanto entre emissores e recetores, mas entre corpos viventes e dispositivos, que, ao mesmo tempo que se colocam questões éticas (a obra perde a sua autoria fundadora para ser veículo pronto de transformação), se percebem questões epistemológicas no sentido do acesso a um dado conhecimento (identificação de relações de poder e saber envolvidas na estratégia de construção da obra). A propósito desta possibilidade, numa reflexão sobre ética e teorias da comunicação, os autores Martino e Marques (2014) lançam a possibilidade de uma interseção entre ética e epistemologia onde emissor e recetor não se ligam através de uma relação simétrica ou assimétrica, mas através de uma estrutura rizomática de interação. Como dizem os autores:

um dos pontos de intersecção entre o ético e o epistemológico revela-se no fato de que a explicação sobre 'o que acontece' pode ser igualmente vista como uma proposição sobre 'o que se deve fazer a partir disso'. Revelam-se no exame das Teorias da Comunicação conceções de um ethos e de formas dissensuais de expressão e interação que inventam modos de ser, ver e dizer, configurando novos sujeitos e novos modos e cenas de enunciação coletiva, naquilo que Esteves (2007) chama de agonística da vida coletiva. (Martino \& Marques, 2014, p. 140)

Independentemente de nos podermos colocar importantes questões perante a perspetiva de interseção entre ética e epistemologia, esta possibilidade reforça-nos a ideia de um movimento responsável, meta-discursivo e distanciado na ligação entre os agentes implicados num fluxo comunicativo.

O entendimento do gesto corêutico como um dizer, como discurso, é a melhor aproximação que poderemos fazer à dança. Afastada, por isso, estará toda a insistência em codificá-la, seja na prática, seja na teoria. E todo o percurso da dança contemporânea deverá levar a dança ao seu próprio estranhamento pela elasticidade com que se alarga e projeta na sua espiral criativa. Ao nos situarmos na abertura do gesto enquanto pura medialidade que se comunica aos homens, desvinculámo-lo, assim, de toda a tentativa de o fixar a um significado, um referencial determinado - abre-se aqui a dimensão ética e uma nova vida da obra enquanto transformação marcada por um posicionamento. Ao mesmo tempo, a medialidade coloca-se como a abertura necessária a uma discussão ontológica do corpo-em-movimento que irá superar, como já o dissemos, a discussão em torno das suas correspondências. Neste sentido, trata-se, no geral, de uma discussão que se coloca mais próxima do que é processual do que o que se dá como instituição, como produto.

Neste quadro expandido do gesto performativo, é no cruzamento disciplinar que melhor poderemos observar conceções específicas de sujeito e das suas relações políticas, e, ainda, meta-reflexivamente, do próprio campo de operações. É o que nos permite o entendimento da obra a partir da noção de dispositivo. A rede, o tipo de rede que se 
estabelece entre os diversos intervenientes da obra é que define o campo crítico a partir do qual a obra renasce. Este devir da obra funciona pela despolarização do gesto em relação ao envolvente e aos objetos materiais (ou seja, o corpo vivente não como centro exclusivo). A dança ou o corpo performativo pode assim expandir-se: ao nível de uma relação entre objetos materiais sem corpo orgânico; ao nível virtual pelas próteses que se possam estabelecer. O gesto passa a ser real ou virtual, visível ou invisível. É o que se processa em obras de autores como William Forsythe (coreografia exclusivamente realizada por objetos ou projetos de dança com as novas tecnologias) ou, noutra lógica, a artista brasileira, Lygia Pape com os seus Balés Neo-concretos (corpo oculto que funciona literalmente como motor).

Em tom de conclusão, poderíamos reforçar aqui a ideia de que, na dança, a passagem de uma dimensão ontológica do gesto a uma ética da forma não significa uma redução nem uma substituição. A deslocação de uma discussão ontológica para uma discussão ética da dança, é apenas uma circulação entre corpo-em-movimento e gesto e é nesta circulação que o corpo dançante se torna devir. Os dois eixos de discussão têm em comum a noção de medialidade como pressuposto fundamental. A importância de pensar a medialidade não apenas como suporte, mas como movimento de inclusão e devolução obriga a: 1) manter qualquer plano discursivo em aberto e a incluir o Outro; 2) despistar as tendências de aprisionamento da obra em categorias; 3) aferir conhecimento pela identificação das estratégias de construção ou dos meta-discursos envolvidos.

Pensar a obra através da noção de dispositivo permite-nos entender estratégias dramatúrgicas das distâncias, como por exemplo a epicidade e a citabilidade, e, desta forma, devolver um gesto pensante (um gesto pensado e pensante), que pode ser discutido numa perspetiva ética sem dependência direta de uma ontologia. A medialidade enquanto produto, o exibido, o dito, transporta em si, como se referiu, a abertura ética. Discutir o gesto nos limites da sua visibilidade. A medialidade, é, pois, o desafio que se coloca a uma performance que se pretende resistente a uma categorização e que dialoga através de um pensamento pós-metafísico. O processo de subjetivação gera sujeitos ativos (políticos). Por outro lado, a discussão ontológica permite-nos recuperar um gesto dançante enquanto gesto colhido, numa revisitação e reinvenção perpétua; um gesto em contínuo movimento que se dá nos limites da visibilidade da sua transmutação em gesto corêutico. Neste jogo de aproximação e de abandono do referente, a obra torna-se instável e impermanente, em constante porvir. É este o seu estatuto ontológico: valor processual e discursivo que nos chama e atrai para olhar e ler a obra como forma expandida, como corpo-em-movimento e percorrer o movimento processual como gesto corêutico: um gesto que interrompe, suspende, situa, se estranha e desconforta. Este gesto, por sua vez, assume-se duplamente como próprio do pensamento e próprio da dança. Neste caso, estamos perante um campo de reprodução do sujeito múltiplo. "

\section{REFERÊNCIAS BIBLIOGRÁFICAS}

Agamben, G. (1997). Notas sobre o gesto. In M. T. Cruz (Ed.), Inter@ctividades (pp. 16-21). Lisboa: C.E.C.L. 
Agamben, G. (2009). O que é o contemporâneo e outros ensaios. Chapecó: Editora Argos.

Barros, N. (2009). Da materialidade na dança. Porto: C.E.A.A./ESAP.

Benjamin, W. (1955). L'Opera d'arte nell'epoca della sua riproducibilità técnica. Torino: Einaudi.

Goldberg, R. (1988). Performance art. Londres: Thames and Hudson.

Humphrey, D. (1959). The art of making dances. NY: Grove Press.

Maffesoli, M. (2011). Pós-modernidade. Comunicação e Sociedade, 18, 21-25.

Mallarmé, S. (1886/1976). Ballets. Igitur -Divagations - Un Coup de Dés. Paris: Éditions Gallimard.

Mallarmé, S. (1893/1976). Autre étude de danse. Les fonds dans de le Ballet. D'après une indication récente. Igitur -Divagations - Un Coup de Dés. Paris: Éditions Gallimard.

Martino, L. M. S. \& Marques, A. C. S. (2014). Ética e teorias da comunicação: Poder, interações e cultura participativa. Comunicação e Sociedade, 25, 138-153.

Martins, F. (2016). Sentido narrativo - Da formatividade à performatividade. Porto: Afrontamento.

Pontremoli, A. (Ed.) (1997). Drammaturgia della danza. Milão: Euresis Edizioni.

Sorell W. (1981). Storia della danza. Bologna: Il Mulino.

Valéry, P. (1957). Philosophie de la danse. In Oeuvres I, Variété - Théorie poétique et esthétique. Paris: Gallimard.

Valéry, P. (1960). L'Âme et la Danse. In Oeuvres II. Paris: Gallimard.

\section{NOTA BIOGRÁFICA}

Né Barros, coreógrafa e investigadora no Instituto de Filosofia, Grupo Estética, Política e Conhecimento (U.P.). Doutorada pela FMH (U.T.L.), Master in dance, Laban Centre City University, Londres. Artisticamente, iniciou a sua formação em dança clássica e mais tarde trabalha dança contemporânea e composição coreográfica, nos Estados Unidos, Smith College. Coreografou para o Balleteatro, Companhia Nacional de Bailado, Ballet Gulbenkian e Aura Dance Company. Professora Auxiliar parcial na ESAP. Tem diversos artigos publicados. Autora do livro Da Materialidade na dança e de Dança: o corpo e a casa, Co-editora de Artes Performativas: Novos Discursos, Das Imagens Familiares, Deslocações da Intimidade. Fundadora e codiretora do festival internacional de cinema Family Film Project e do Balleteatro.

E-mail: nebarros@gmail.com

Rua do Ouro, 108, apt 5.5 4150-552 Porto, Portugal

$\because$ Submetido: 30-09-2016

$*$ Aceite: 22-01-2017 